Revista Mídia e Cotidiano

ISSN: 2178-602X

Entrevista

Volume 15, Número 2, maio/ago. de 2021

Submetido em: 22/11/2020

Aprovado em: 12/05/2021

\title{
Raúll Fuentes Navarro: contribuições ao campo acadêmico da comunicação
}

\section{Raúl Fuentes Navarro: contributions to the academic field of communication}

\section{Raúl Fuentes Navarro: contribuciones al campo académico de la comunicación}

\author{
Antonio Carlos de SOUZA ${ }^{1}$
}

\section{Resumo}

Raúl Fuentes Navarro, professor e pesquisador mexicano, tem se dedicado a investigar a pesquisa da comunicação e a profissionalização da área, na América Latina, de modo geral, e no México, de modo específico. Por causa desse interesse, suas investigações estão voltadas para Teorias da Comunicação, Epistemologias da Comunicação e Metodologias de Pesquisa em Comunicação. As décadas de dedicação à área levaram à produção de 26 livros, 85 capítulos e mais de 120 artigos em revistas especializadas. Nesta entrevista, Fuentes Navarro compartilha algumas impressões sobre os desafios para estudar a comunicação em países latino-americanos.

Palabras-clave: Comunicação. Entrevista. América latina.

\begin{abstract}
Raúl Fuentes Navarro, a Mexican professor and researcher, has dedicated himself to studying communication research and the professionalization of the area, in Latin America, in general, and in Mexico, in a specific way. Because of this interest, his investigations are focused on Communication Theories, Communication Epistemologies and Communication Research Methodologies. The decades of dedication to the area led him to publish 26 books, 85 chapters and more than 120 articles in specialized magazines. In this interview, Fuentes Navarro shares some impressions about the challenges of studying communication in Latin American countries.
\end{abstract}

Palavras-chave: Communication. Interview. Latin America.

\section{Resumen}

Raúl Fuentes Navarro, profesor e investigador mexicano, se ha dedicado a estudiar la investigación en comunicación y la profesionalización del área, en América Latina, en general, y en México, de manera específica. Debido a este interés, sus investigaciones se

\footnotetext{
${ }^{1}$ Mestrando em Comunicação e Práticas de Consumo pela Escola Superior de Propaganda e Marketing SP. Participa do grupo de pesquisa BIOCON - Bolsista Capes. E-mail: antonio.carlos@acad.espm.com. ORCID: 0000-0002-6437-8227.
} 
centran en Teorías de la comunicación, Epistemologías de la comunicación y Metodologías de investigación de la comunicación. Las décadas de dedicación al área llevaron a la producción de 26 libros, 85 capítulos y más de 120 artículos en revistas especializadas. En esta entrevista, Fuentes Navarro comparte algunas impresiones sobre los desafíos del estudio de la comunicación en los países de América Latina.

Keywords: Comunicación. Entrevista. América Latina.

\section{Apresentação}

O Dr. Raúl Fuentes Navarro é um importante fomentador da investigação científica e da formação de profissionais em comunicação na América Latina, especialmente no México. Com uma trajetória acadêmica de mais de 40 anos, é pesquisador e professor do Departamento de Estudos da Comunicação Social, no Centro Universitário de Ciências Sociais e Humanidades, na Universidade de Guadalajara. Sua atuação na área o levou a publicar 26 livros, 85 capítulos e mais de 120 artigos em revistas especializadas.

Desde o ano de 1996, é membro do Sistema Nacional de Investigadores (SNI) do Consejo Nacional de Ciencia y Tecnología (Conacyt). Em 2006, foi promovido a pesquisador nacional nível III (máximo), categoria para a qual teve seu nome renovado por mais 15 anos (2018-2032). Por sua destacada contribuição, foi eleito avaliador integrante da Comisión Dictaminadora del Área V (Ciências Sociais) do SNI nos períodos 2006-2008 e 2018-2020.

Entre seus títulos, destaca-se o de membro regular da Academia Mexicana de Ciências, desde o ano de 2005. Em 2007, recebeu a Medalha da Asociación Mexicana de Investigadores em Comunicação (AMIC), a principal associação no México dedicada à pesquisa acadêmica de comunicação, em reconhecimento aos seus 25 anos de trajetória acadêmica. Recentemente, em 2019, foi eleito vice-presidente da Associación Iberoamericana de Investigadores de la Comunicación. No mesmo ano, o Conselho Universitário da Universidad Autónoma de Baja Califórnia concedeu-lhe o título de Doutor Honoris Causa.

Seus textos, considerados obras de referência na formação de comunicólogos, têm alcançado países da América do Norte, América Central, América do Sul e Europa. Fuentes Navarro já participou de mais de 200 conferências pelo mundo, incluindo o Brasil. Em 2020, foi o conferencista principal da $29^{\mathrm{a}}$ Compós, realizada remotamente pela 
Universidade Federal do Mato Grosso do Sul, onde ele já tinha estado como pesquisador visitante.

Nesta entrevista, realizada por e-mail, ele compartilhou suas impressões sobre alguns dos maiores desafios para a institucionalização e a profissionalização da comunicação, particularmente na América Latina.

\section{Entrevista}

A.SOUZA: Quais são os principais desafios teóricos e metodológicos para a comunicação na América Latina no século 21?

NAVARRO: O mesmo que em qualquer outra parte do mundo. Nem para o exercício diversificado e múltiplo da comunicação na sociedade, nem para sua investigação sistemática e rigorosa, existem particularidades teóricas ou metodológicas segundo a geografia. Antes, essas particularidades decorrem dos quadros axiológicos (valores) e dos preconceitos ideológicos associados a essas práticas socioculturais (tanto comunicacionais quanto acadêmicas). De qualquer forma, os desafios para a América Latina devem ser enfrentados localmente, sem desconsiderar suas articulações globais.

A.SOUZA: Qual é a melhor conceituação para a disciplina: "Ciências da Comunicação" ou "Campo Comunicacional”?

NAVARRO: Os termos se referem a dois objetos muito diferentes. "Ciências da Comunicação" é um dos nomes dados a projetos de constituição disciplinar, especialmente em termos de ensino e pesquisa. "Campo da comunicação" inclui dimensões disciplinares (científicas, acadêmicas, referenciais etc.), mas também articulações políticas, econômicas, culturais etc. dos exercícios específicos (jornalístico, político, organizacional, entretenimento etc.). 
A.SOUZA: A partir do conceito de interdisciplinaridade, a comunicação dialoga com outras disciplinas das ciências sociais. Nessa relação, há uma troca de saberes num processo que deveria ser colaborativo e profícuo. Com essas considerações, é pertinente observar se há, ainda, marginalidade nas pesquisas de comunicação, marginalidade na comunicação em relação a outras ciências sociais e marginalidade na pesquisa científica em relação ao desenvolvimento da América Latina? E, aproveitando o contexto da pergunta, quanto os cortes em investimentos na área corroboram para a perenidade ou não desse cenário? Cito esses cortes nos investimentos nas pesquisas em ciências humanas, mais especificamente, considerando o momento político do Brasil.

NAVARRO: A interdisciplinaridade é uma condição indispensável para todas as disciplinas de todos os lugares, mas deve ser concretizada em ações e práticas científicas e acadêmicas concretas que, como todas as práticas sociais, estão sujeitas a relações de poder ... os processos sociais, do ponto de vista ideal, eles teriam que ser colaborativos, horizontais, produtivos... mas é praticamente impossível verificar isso. A "marginalidade" dos estudos da comunicação, bem como a crescente "centralidade" de suas práticas sociais, é uma condição relativa aos “capitais" acumulados e colocados em prática nas práticas. Boa parte dos "cortes" que se manifestam em muitos países (também, seriamente, no México) são expressões nas políticas públicas dessa marginalidade reconhecida e reforçada pelo poder.

A. SOUZA: Como um desdobramento do tema anterior, pergunto: como fornecer, na realidade atual de nossos programas de pós-graduação em Comunicação, apoio aos estudantes para o bom desempenho de suas investigações, de modo a que suas teses e dissertações alcancem resultados relevantes, com encaminhamentos metodológicos adequados? 
NAVARRO: A única maneira que conheço, nesse sentido, é o acompanhamento crítico: que as experiências coletivas e individuais relevantes possam ser contrastadas e assimiladas a cada momento da decisão e que desenvolvam competência crítica. Metodologia é a arte de tomar decisões em todos os momentos do processo de pesquisa e deve ser aprendida na comunidade, porque é a única maneira de não reproduzir acriticamente os procedimentos, mas de tomar decisões sempre revisáveis.

A.SOUZA: A partir disso, poderia abordar a questão das necessidades gerais, abrangentes e transversais de uma formação metodológica básica para que o processo de pesquisa seja assertivo?

NAVARRO: Como eu disse na resposta anterior, a chave distintiva da prática científica (em qualquer disciplina) é a reflexividade metodológica: saber tomar decisões e explicá-las diante das opções de cada operação específica. É isso que constitui a "identidade" científica, pertencente a uma determinada comunidade ... eu gosto muito de como Andrew Abbott (2004) explica: "Ciência é uma conversa entre o rigor e a imaginação. O que um impõe ao outro é avaliado. Qualquer avaliação leva a novas propostas, e assim por diante...”.

A.SOUZA: Há muitos debates em torno do uso, validação e do reconhecimento das epistemologias do Sul, um Sul Global (não geográfico), mais conceitual, que abarcaria outros saberes, como os conhecimentos não científicos que são ignorados - por exemplo, os das comunidades indígenas, não validados e, geralmente, não utilizados em artigos, dissertações e teses, por correrem o risco de serem vistos como trabalhos menores ou de expressão menor. Quais perspectivas e quais posicionamentos deveriam ser adotados ou discutidos pelas universidades, pesquisadores, estudantes e pela comunidade acadêmica de modo geral a respeito disso? 
NAVARR0: Penso que todos esses sistemas, mais ou menos rigorosos, do conhecimento social devem ser analisados e talvez praticados, criticamente, iguais ou não aos sistemas científicos hegemônicos... O que não é produtivo na universidade é o dogmatismo, o "pensamento único". Além de negar a essência da universidade, que também nega a "essência" da comunicação, que não é a imposição da "verdade", mas a "produção social de significado". Os debates epistemológicos são valiosos e indispensáveis, neste momento, ao tentar impedir o pensamento crítico de vários ângulos.

A.SOUZA: Um dos apontamentos que o senhor fez em outras entrevistas (RODRÍGUEZ-MILHOMENS, 2015; TRUJILLO, 2010) é que as pesquisas da América Latina, nos anos 1970, puderam contribuir de maneira decisiva e bastante salutar com os estudos da comunicação, e que esta curva era ascendente mas, com o passar do tempo, essa contribuição passou a ser mais linear e não sei dizer se estagnada. Entre alguns fatores apontados, estaria a falta de união dos pares na América Latina, a quantidade de temas divergentes, a falta de debates com o intuito de uma agenda em comum e a diáspora dos profissionais [pesquisadores e professores] da América Latina. Qual é a sua leitura desse cenário, no século XXI? Essa exportação de profissionais e a não manutenção de pesquisadores na América Latina também não poderiam contribuir de maneira positiva com esse intercâmbio, para construção, divulgação e desenvolvimento das pesquisas latinas, mesmo considerando a perda e a desvalorização desse capital?

NAVARRO: A fragmentação é uma tendência geral nas ciências contemporâneas e, entre nós, com tradições científicas muito fracas, é muito mais negativa em seus efeitos, porque pode facilmente perder seu significado... há muitos interesses em jogo e a confusão favorece a maioria deles. É mais difícil ser crítico, porque é muito mais fácil ser a favor ou contra, mas 
sem debate... A “América Latina” é uma imagem do futuro (produzida, é claro, fora de nossos países, nos Estados Unidos e na França, em tudo, quase não tem relação com Bolívar ou Che...), que tinha melhores pontos de apoio (políticos e culturais) há 50 anos e agora mostra a difícil integração entre países tão diversos e complexos... Assim como não há uma única "investigação" "americana", "europeia” ou "asiática", não ajuda em nada afirmar uma "investigação latino-americana". Melhor, para promover conversas, diálogos entre vários, reconhecimento mútuo. E acho que no campo da comunicação na América Latina há exemplos e resultados muito melhores que o do século passado... A fragmentação e a incapacidade de impor e aceitar visões autoritárias ajudam muito.

A. SOUZA: Ao longo da sua carreira e trajetória, é nítida a sua dedicação e preocupação com o estudante de comunicação e com o fazer deste profissional (comunicólogo) que, de certa forma, em algum momento, estará inserido no mercado de trabalho. Estamos vivendo uma reconfiguração nas formas de trabalho e prestação de serviços. As políticas neoliberais que incentivam os indivíduos a ser empreendedores de si, o advento de novas tecnologias, plataformas para se comunicar e agora tensionados por um momento muito complicado, a pandemia de Covid-19, que nos obriga a repensar todas nossas dinâmicas de interação. Refletindo sobre a importância social e política que a disciplina tem, quais são as perspectivas de futuro para a profissão e quais são as demandas mais emergentes no mercado de trabalho contratante e os desafios que se impõem no ambiente acadêmico e na formação curricular e intelectual desses estudantes e futuros profissionais?

NAVARRO: Todos esses fatores que determinam os mercados de trabalho (relações oferta-demanda) são flutuantes e diversificados. Adicionar as análises por região ou país pouco ajuda para entender quais são as melhores e as piores opções em um determinado momento e num determinado lugar. A 
situação em São Paulo não é a mesma de Manaus, para colocar dois casos, ou na Cidade do México e Guanajuato, para mencionar outros, mexicanos. E, obviamente, não é o mesmo no final de 2019 como agora, seis meses depois... A pandemia é uma condição extraordinária, porque TODAS as práticas e costumes, em TODOS OS países e regiões, de TODAS as perspectivas políticas, ideológicas, profissionais etc. eles devem ser reformulados AO MESMO TEMPO EM TODA PARTE. Não sabemos a que padrões de comportamento ou participação serão relevantes para o futuro imediato (porque acreditamos que haverá um futuro imediato). E, se esperamos que a incerteza seja combatida por uma MENSAGEM ÚNICA, MÉDIA OU MÉTODO VERDADEIRO, não haverá futuro, pelo menos para aqueles que esperam isso.

A.SOUZA: Dentro deste cenário que está em profunda mutação - de forma acelerada, tensionado por diversas variáveis políticas e tecnológicas, pelo acesso a uma infinidade de dados que, de certa forma, não se sabe como devem e podem ser manipulados, pela presença da Covid-19), podemos ser otimistas? É possível pensar em futuro auspicioso e vislumbrar a construção ou a oportunidade de uma utopia com relação à comunicação?

NAVARRO: Acredito que podemos e devemos ser otimistas, mas não ingênuos. Agora é quando é mais necessário ser crítico, isto é, ser capaz de identificar opções, alternativas e compartilhar as consequências. Todas as dimensões da realidade estão em risco, e a desarticulação racionalista (não "neoliberal”) que separou o "econômico", o "político", o "cultural”, o "biológico", o "tecnológico" não ajuda o "comunicacional", embora nem a confusão entre um e outro, talvez também nessa escala "macro", sirva a proposta da ciência como uma conversa entre o rigor e a imaginação. Espero. 


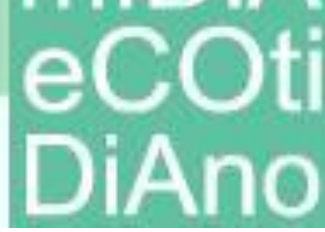

\section{Referências}

ABBOT, Andrew. Methods of Discovery: Heuristic for the Social Sciences. New York: W. W. Norton \& Company, 2004.

RODRÍGUEZ-MILHOMENS, Graciela. Cultivador de preguntas de comunicación. Revista de Comunicación, 2015. Disponível em:

https://www.researchgate.net/publication/326718457_Entrevista_a_Raul_Fuentes_Navarro_Inv estigador_de_comunicacion. Acesso em: 15 maio 2021.

TRUJILLO, Janny Amaya. Entrevista a Raúl Fuentes Navarro: Campo académico, formación profesional y proyecto social... ¿Desde dónde replantearse la utopía de la comunicación?

ALCANCE Revista Cubana de Información y Comunicación, v. 2, n. 2, 2010. 